\title{
The Madagascar International Cooperative Biodiversity Group (ICBG): Using natural products research to build science capacity.
}

\author{
James S. Miller, Christopher Birkinshaw and Martin Callmander
}

\begin{abstract}
In 1993, the National Institutes of Health funded a program to support multi-institutional partnerships to conduct natural products drug discovery in a manner to support conservation and economic growth. To date, ten International Cooperative Biodiversity Groups (ICBG) have been supported. The activities of the Madagascar ICBG project are reviewed, first providing an overview of goals of the program to conduct botanical inventory, conservation analysis, and to collect samples for bioassay in Madagascar's northern complex, then focusing on efforts to build capacity to conduct these activities within Madagascar. This paper introduces the results of a recently conducted ethnobotanical training program.
\end{abstract}

\section{Introduction}

Three federal agencies of the United States government, the National Institutes of Health (NIH), the National Science Foundation (NSF), and the U.S. Agency for International Development (AID), launched a program in 1992 to support modern natural products drug discovery programs. But, the program went beyond conventional models and aimed to promote conservation of biological diversity and encourage economic development through partnerships between biologically rich tropical countries and technology rich research institutions in the United States, a target necessary to ensure that discovery was sustainable and equitable (Rosenthal 1997, Rosenthal et al. 1999; see also: www.fic.nih.gov/programs/icbg.html). The International Cooperative Biodiversity Groups (ICBG) were intended to be multi-institutional consortia that brought together expertise in biological survey and inventory, natural products discovery and development, and conservation and development. Following peer review of applications, five such programs were funded by the Fogarty International Center of NIH in 1993 and 1994. The program was re-competed in both 1998 and 2003 with some turnover in programs. In addition, seven two-year planning grants were awarded in 2003 with the goal that these would compete for comprehensive support in 2005. To date, there have been ten comprehensive awards and five programs in Madagascar, Panama, Vietnam and Laos, New Guinea, and Uzbekistan and Kyrgyzstan remain active.

In 1993, a group headed by Dr. David Kingston, from the Virginia Polytechnic Institute and State University (VPI), and including the Missouri Botanical Garden, Conservation International, Bristol-Myers Squibb, and Bedrijf Geneesmiddelen Voorziening Suriname (BGVS) were funded by NIH to work in Suriname. The Suriname project was successful in collecting, extracting, and assaying plant samples, in conducting significant botanical inventory, and in conducting meaningful training, but there were difficulties getting permits to continue the program and in 1998, a new application to NIH proposed transitioning the program to Madagascar, where the Missouri Botanical Garden had a more established research and conservation program and a strong relationship with the Malagasy government.

\section{Correspondence}

James S. Miller, Missouri Botanical Garden, St.Louis, Missouri, U.S.A. james.miller@mobot.org

Chris Birkinshaw, Missouri Botanical Garden, BP3391, Antananarivo 101, MADAGASCAR. chris.birkinshaw@mobot-mg.org

Martin Callmander, Missouri Botanical Garden, St.Louis, Missouri, U.S.A. martin.callmander@unine.ch

Ethnobotany Research \& Applications 3:283-285 (2005) 
During the period from 1998 to 2003 , permission was obtained from the government of Madagascar for the collection and export of plant samples and extracts and a program was established for the collection of plants in the vicinity of the Zahamena National Park in the wet forests along the escarpment to the east of the capital of Antananarivo. In 2003, the NIH renewed support for the program and the effort was moved to a new geographic location within Madagascar and now aimed to study and conserve endangered forest types in northern Madagascar.

\section{The Northern Complex}

Madagascar, the world's third largest island, is home to perhaps 13,000 plant species (Goodman \& Benstead 2005) with probably more than $90 \%$ of them found nowhere else in the world (Gautier \& Goodman 2003). Unfortunately, less than $10 \%$ of original vegetation cover in Madagascar still exists and the majority of the landscape in the country is seriously degraded (Myers et al. 2000). The current ICBG effort focuses on northern Madagascar, a center of endemism within the country because of the varied geology, soil types, and climate in the region (Rossi 1976). Like other high biodiversity sites in Madagascar, remaining forests outside of the existing protected area network have been significantly reduced in area and are highly threatened by shifting cultivation, fire, and other unsustainable practices resulting from rapidly growing human populations in the area. Most of the forest patches north of $13^{\circ} 30^{\prime} \mathrm{S}$, with the exception of the protected areas at Montagne D'Ambre, Foret D'Ambre, Analamerana, and Ankarana, are relatively small and fragmented. Throughout the rest of the this paper, these unprotected patches of forest in northern Madagascar will be referred to as the Northern Complex.

\section{Current program goals}

The Missouri Botanical Garden's Botanical Inventory, Sample Collection, and Conservation program included the following specific goals:

1. The collection of plant samples for natural products discovery efforts from northern Madagascar forests.

2. To recollect material of species that prove of interest in initial assays and are identified as candidates for further pharmacological investigations.

3. To conduct comprehensive botanical inventories and analyze species distributions to identify rare and threatened plant species from currently unprotected parcels of forests in northern Madagascar.

4. To use the information on distribution of rare and threatened plant species to help define priority areas for plant conservation in the northern complex.

5. To use the results of conservation analyses to attempt to obtain protected area status for the most important remaining forested areas in the Northern Complex
6. To promote the development of the Malagasy botanical research community, including improvement of institutional facilities and by providing opportunities for professional development for Malagasy scientists.

7. To develop mechanisms to ensure appropriate participation by member of local communities in the design and implementation of research, natural products, and conservation activities.

\section{Challenges - integrating inventory and discovery with development and conservation}

The combination of research and development/conservation goals has required a concerted effort to integrate these activities. Although there may be synergy that results from combining these goals, their integration is far from automatic. Through collective experience in the program, it has become clear that better knowledge of the flora achieved by botanical inventory can only help ensure the gathering of a taxonomically and chemically diverse set of plant samples for bioassay. Inventory work can also help support conservation by providing information on species distribution and abundance that can then be used to locate those areas most critical for maintaining the maximum number of species in protected areas. This research is particularly opportune at a time when the conservation community in Madagascar are debating tripling the area of the country's protected areas in response to President Marc Ravalomanana's declaration at the National Parks Congress in Durban in 2004.

One facet of conservation efforts has been to address growth and development of science capacity in Madagascar. Like many tropical, developing countries, Madagascar has inadequate scientific infrastructure. There are not enough scientists, many would benefit from additional training, and most currently work in institutions without adequate operating funds. Throughout the Madagascar ICBG there have been a series of efforts to help obtain needed equipment and supplies for partner institutions and provide opportunities for professional development. These have included:

1. Regular workshops on botanical inventory and fieldwork techniques.

2. Regular workshops on management of plant collections and specimen identification.

3. Hands on individual training in both the field and herbarium.

4. An introduction to ethnobotany as a means of integrating conservation with local communities.

\section{The present workshop and results}

Largely because of previous workshops, other training exercises, and significant field experience, the community of Malagasy botanists associated with the ICBG project are quite competent with field botany, specimen identification, and collections management. However, there has been 


\section{Miller et al. - The Madagascar International Cooperative Biodiversity Group (ICBG): Using natural products research to build science capacity}

little training available in ethnobotany. Local experience has largely been limited to recording locally used common names and uses. There has been little experience with hypothesis driven ethnobotanical questions and structure of interaction with local informants.

The development goals of the ICBG include the aim of including local communities in conducting research and improving their understanding and use of natural resources. This ICBG project undertook the effort of conducting an ethnobotanical workshop to: 1) improve how local staff thought about interaction with local communities; 2) to provide rigor to information that was gathered from villages in proximity to project activities and ensure that local communities were better incorporated into the project decision making process when activities might have some influence on their lives.

Drs. Will McClatchey and Lisa Gollin, both of the University of Hawai'i, traveled to Madagascar in March of 2005 to conduct a two-week training program covering an introduction to ethnobotany, review of subjects likely to be of interest to the ICBG group, and a week of practical field experience (McClatchey \& Gollin 2005). The first week of instruction was taught in a classroom at the Centre National d'Applications et des Recherches Pharmaceutiques, an ICBG partner in Anatanarivo. This was followed by a week of field experience with the community living around Analalava Forest, a fragment of humid evergreen forest $7 \mathrm{~km}$ west of Foulpoint on Madagascar's east coast. The contributed papers in this issue report on the individual studies that were conducted as a part of the workshop.

\section{Future challenges}

The workshop was enthusiastically received and there was strong follow through on the field projects as the papers that follow attest. Particularly novel was the approach that considered the local communities as research partners rather than research subjects. The challenge will be to incorporate the lessons from the workshop in future ICBG activities. Several efforts will be made to ensure that this happens. The participants included ICBG staff, but also others with whom the project may interact with varying degrees of frequency. In an effort to keep those involved with the workshop thinking about the lessons and continuing their education in this area, a rendevous of the attendees is planned for March of 2006 to review progress. There are also meetings scheduled at the annual ICBG meeting, to be held about the same time that will review project interactions with local communities.

\section{Acknowledgements}

Financial support for the ICBG project was provided by the National Institutes of Health, the National Science Foundation, and the U.S. Department of Agriculture un- der Grant No. U01 TW/CA00313. Joshua Rosenthal and Flora Katz, of the Fogarty International Center, NIH, and Yali Hallock, of the $\mathrm{NCl}$, and James Rodman, NSF, have provided tremendous support and encouragement for the ICBG project. Activities essential to the ICBG, including plant collecting, are conducted under a collaborative agreement with the Centre National d'Applications et des Recherches Pharmaceutiques, Antananarivo, Madagascar. We gratefully acknowledge courtesies extended by the Government of Madagascar (Direction Générale de la Gestion des Resources Forestières).

\section{References Cited}

Gautier, L. \& S.M. Goodman. 2003. Introduction to the Flora of Madagascar. Pp. 229-250 in The Natural History of Madagascar. Edited by S.M. Goodman \& J.P. Benstead. The University of Chicago Press, Chicago.

Goodman, S.M. \& J.P. Beanstead. 2005. Updates estimates of biotic diversity and endemism from Madagascar. Oryx 39:73-77.

McClatchey, W.C. \& L.X Gollin. 2005 An Ethnobotany Research Training Workshop in Madagascar. Ethnobotany Research and Applications 3:309-327.

Myers, N., R.A. Mittermeier, ID.G. Mittermeier, G.A.B. Da Fonseca \& J. Kent. 2000. Biodiversity hotspots for conservation priorities Nature 403:853-858.

Rosenthal, J. 1997. Integrating drug discovery, biodiversity conservation, and economic development: early lessons from the international cooperative biodiversity groups. Pp. 281-301 in Biodiversity and Human Health. Edited by F. Grifo \& J. Rosenthal. Island Press, Washington, D.C.

Rosenthal, J.P., D. Beck. A. Bhat, J. Biswas, L. Brady, K. Bridbord, S. Collins, G. Cragg, J. Edwards, A. Fairfield, M. Gottlieb, L.A. Gschwind, Y. Hallock, R. Hawks, R. Hegyeli, G. Johnson, G.T. Keusch, E.E. Lyons, R. Miller, J. Rodman, J. Roskoski \& D. Siegel-Causey. 1999. Combining high risk science with ambitious social and economic goals. Pp. 6-21 in Drug Discovery, Economic Development and Conservation: The International Cooperative Biodiversity Groups. Edited by J.P. Rosenthal. Pharmaceutical Biology 37:supplement.

Rossi, G. 1976. Problèmes biogéographiques de l'extrême-Nord de Madagascar. Rev. Géogr. (Madagascar). 28:133-154. 
